\section{Guia de Turismo: o Mérito da Profissão}

\section{Ivone Selva Santos Canani ${ }^{1}$}

RESUMO: Mostra aimportância do exercício da profissão de guiade turismo no Brasil como elemento propiciadorde qualidade nos serviços turísticos desenvol vidos por Agências de Turismo c outras empresas do setor. Destaca a necessidade da existência de agentes para orientar e acompanhar turistas, de modo a apresentar a imagem das localidades visitadas e os serviços of crecidos proporcionando ao visitante momentos de lazer e satisfação. Analisa a atuação desse profïssional buscando sempre a melhoria da prestação de serviços.

PALAVRAS-CHAVE: guia de turismo, qualidade de serviços turísticos, profissional de turismo.

ABSTRACT: Display the importance of tourism guide profession practice in Brazil like a component to offer quality about tourists services developed by travel Agencies and Enterprises connected to the tourism. Stand out the necessity of agents existence to direct and accompany tourists to present the image of the visited places and service offering to the visitor moments of leisure and satisfaction. Analyse this rrofessional acting always searching the best in service offering.

KEYWORDS: guide of tourism, tour condutor, quality of tourist services, professional of tourism.

\section{Introduçāo}

Quando se fala em turismo, logo vem à mente uma série de associações. Turismo evoca bem-estar, lazer, divertimento, temperatura amena, natureza, cultura etc. São todas associações positivas. Poucas palavras - em qualquer língua possuem tal riqueza simbólica para tantas (e cada vez mais) pessoas. Isto ć assim para um leigo no assunto, mas quando a pessoa é um profissional da área de Turismo além das associações gratas - evoca uma série de problemas: sazonalidade, ciclo de vida, crise, atendimento, etc.

Focalizando com preferência o atendimento, este artigo pretende demonstrar a importância de um profissional, entre os recursos humanos envol vidos com turismo, que tem a seu cargo a efetivação dos serviços propostos ao cliente consumidor. Tratase de um elemento-chave: o guia de turismo. Essa pessoa indica, acompanha, orienta e mostra locais ao visitante, de acordo com o que a agência oferece. Cabe-lhe fazer cumprir os programas e, dessa forma, mostrar a imagem da instituição, da cidade e do produto final. Ao mesmo tempo, busca-se resgatar a imagem desse profissional que atua muitas vezes com poucos méritos devidamente reconhecidos pelas empresas Pretende-se ainda analisar as características dessa profissão que permitem a realização correta das suas funções específicas e, ao mesmo tempo, verificar a necessidade de uma capacitação adequada, obtida junto ao Instituto Brasileiro de Turismo (Embratur).

Paralelamente, será apresentada a trajetória desse profissional em âmbito nacional e seu papel como executor de um programa efetivo de qualidade no atendimento, assim como seu relacionamento com o turista e interação com os demais profissionais da área. Finalmente, delinear-se-á o seu perfil, chegando às considerações finais e referências bibliográficas.

O embasamento deste artigo deriva de consultabibliográfica, mas também são apresentadas situações e experiências advindas da prática pessoal da autora, que exerce as atividades de guia de turismo ${ }^{2}$.

\section{Guia de Turismo e Serviços Turísticos}

Quando se pensa em turismo há inúmeras interpretações, pelas empresas envolvidas, sobre como desenvolvê-lo, onde, que tipo de equipamentos usar, quais

2. Cadastrada junto à Embratur desde 1986, vem exercendo a profissão de guia de turismo local, regional de excursão nacional e excursão internacional, realizando passeios e viagens como autônoma contratada pelas empresa Turinter Viagense Promoçōes, de Porto Alegre, RS; BAL-CAM Turismo e Turiskarr de Balneário Camboriú; Ritse Turismo, de Blumenau; Portal Turismo de Itajai; Vera Viagense Turismo, de Brusque, SC. Circuitos desenvolvidos: internacionais (Europa, Estados Unidos, Caribe, Chile, Argentina , Paraguai e Uruguai); nacionais (Nordeste do

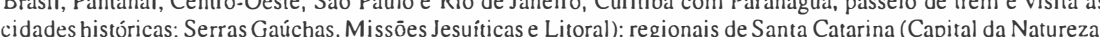
Rota do Sol Caminho dos Prícipes. República Juliann, Vale Europeu, Serras Catarinenses, Contestado e Nova Rota das Termas); local de Balneário Camboriú e Porto Alegre.
1. Licenciada em Letras. Português/Espanhol. pela Pontifícia Universidade Cittólica do Rio Grande do Sul. Especial istaem Lazer e Recreação pela Universidade Federal do Rio Grande do Sul. Guia de Turismo pelo SENAC do Lazer da Universidade do Vale do ltajai. Instrutora nos cursos de Guia de Turismo Nacional e Regional do SENAC. Mestrinditem Turismoe Hotelaria no Mercosul na Universidade do Vale do Itajai.

Ru 2300 974101 - Balnério Camboriú Santa Caturina - 88330-000 Tel: (047)3662876/99853015 E-mail: canani@zaz.com.br / http://www.bnu.nutecnet.com.br/usuarios/canani/ 
os serviços essenciais, quanto haverá de render... etc. Não sem razão se diz categoricamente hoje em dia que turismo é a maior atividade em desenvolvimento no mundo. Segundo Andrade (1995):

Turismo é o conjunto de serviços que tem por objetivo o planejamento, a promoção e a execução de viagens, e os serviços de recepção, hospedagem e atendimento aos individuos e aos grupos, fora de suas residências habituais.

As agências de viagens, visando proporcionar a seus clientes perfeitas condições de satisfação e prazer durante a viagem e agradáveis recordações ao final, buscam sempre os melhores meios de hospedagem, serviços de alimentação, entretenimento, transportes e, é claro, o melhor atendimento, Para obter esse atendimento diferenciado e eficaz, a presença do guia de turismo se torna indispensável.

A missão desse profíssionalé coordenar os meios para que os turistas possam aproveitar ao máximo sua viagem. Ele indica, acompanha, esclarece, aconselha viajante, fazendo com que este aproveite o que de melhor há em cada visita efetuada

Assim os novos conhecimentos, que representam ilusões, sonhos, anseios, podem ser amplamente realizados.

As empresas que contratam guias capacitados, como o são os credenciados pela Embratur, sabem que a qualidade dos serviços prestados terão retorno sob o aspecto propaganda direta feita "boca a boca" pelo cliente satisfeito e consequentemente, haverá a aprovação do consumidor. Esse elemento orientador atingirá os anseios do cliente, dando um destaque especial à viagem, através de seu conhecimento sobre aspectos históricos, geográficos, sociais, culturais, políticos e econômicos, a respeito das localidades visitadas, além de demonstrar sua capacidade em conquistar e atender aos turistas

Só existe um critério para a avaliação da qualidade de serviço: é aquele definido pelos consumidores. Assim se pode dizer que a qualidade do serviço, percebida pelos consumidores, pode ser definida como a extensão das discrepâncias entre as expectativas e desejos dos clientes e suas percepçōes (Yasoshima, 1997).

O papel deste personagem é de suma importância para a consecução de qualquer plano de viagem turística e, no entanto, apesar de representar qualidade, ele é pouco valorizado pelas empresas, que muitas vezes não o contratam para suas excursões. É preciso resgatar sua imagem e atuação junto aos consumidores e tornase importante analisar as funçōes específicas da profissão de guia, sua importância e o papel que desenvolve em relação à sociedade, como prestador de serviços. Devese também considerar que cabe a esse profissional a obrigação de atender bem ao cliente da empresa que o contrata, corroborando o que Giacomini Filho(1997) afirma em seu artigo sobre a empresa turística voltada ao atendimento:

o atendimento é um fator não somente importante, mas sim essencial para a conquista e manutenção do cliente e também dos demais envolvidos no processo turístico.

Como todo profissional, o guia de turismo precisa de aprendizagem que lhe proporcione condiçōes de atuar com eficiência. Ele faz cumprir o programa, apara as arestas dos desconfortos prováveis e possíveis, trata de resolver os problemas junto à agência e serviços contratados, para satisfazer o passageiro. O que ocorre nos bastidores não chega ao conhecimento do cliente e tudo deve ser resolvido. Os méritos? Recebe-os a agência, pois soube organizar a viagem, realizar os contatose principalmente, soube escolhero guia. Ambos devem trabalhar juntos, ter em mente os mesmos objetivos, buscar o que seja melhor para o turista. Um bom trabalho, um desempenho adequado, no que se refere à qualidade no atendimento, farão a fidelidade do cliente para a agência.

Giacomini Filho(1997), defineatendimentodeclarando que:

(...) a manutenção e conquista de clientes, nesta ordem, talvez seja a maior contribuição que o modelo voltado ao atendimento pode propiciar a uma empresa. Isto porque, dentre outros indicadores, os consumidores decidem a compra (e a não-compra) de muitos serviços ou produtos em função do atendimento.

O guia de turismo é, sem dúvida, o melhor vendedor, via direta, para a agência, através do atendimento que proporciona ao grupo com que trabalha. Espera-se que, a longo prazo, as empresas turísticas sintam a necessidade da parceria com este profissional. É preciso que a sua imagem, como um mero indicador, seja modificada pela sua real função: apoiar, acompanhar, esclarecer e vivenciar, junto ao turista, o mesmo desejo de satisfação e prazer que este tem.

\section{Profissāo de Guia de Turismo}

Ataíde Rodrigues Lopes (1994) dispõe-se a dar um toque de humor ao tema em questão, quando narra o resultado de uma reunião com bacharéis de turismo, marketing, propaganda e publicidade, em que uma das equipes chegou a afirmarque:

(...) o primeiro casal de turistas do mundo foi Adão e Eva. Está escrito no Gênesis, que o Senhor os colocou em um paraiso, longe de todas as preocupaçōes humanas, sem filhos, emprego, sogra, governo, impostos e, ainda por cima, poder andar nus, sem nenhum constrangimento. Eles viviam realmente em um paraiso. 
Propôs-se esse exemplo pois as operadoras turísticas e agentes de viagens prometem para seus clientes o paraíso como forma suprema de viver...

A té poder andar nu já faz parte da promessa turistica nos dias de hoje. Se Adão e Eva foram os primeiros turistas, o Paraiso foi o grande Parque Temático da Criaçāo (Lopes, 1994).

Assim sendo, a profissão do guia de turismo deve ter surgido como indicador e acompanhante. Diversas citações existem com exemplos sobre turismo em épocas antigas:

Historicamente têm-se noticias que na época dos turistas romanos que procuravam lugares históricos e religiosos, costumavam visitar templos gregos, iam ao Egito para visitar as Pirâmides, a Esfinge e o Vale dos Reis, como fazem os turistas atuais. Também, naquela época havia atrativos turisticos; alguns sacerdotes ensinavam os crocodilos sagrados a aparecerquando eram chamados e abrir asbocas para mostrar os aguçados dentes aos turistas. Já naquela época os turistas queixavam-se das condiçōes das pousadas, de alguns guias, e muitos deixavam seus nomes gravados nos monumentos (Serviço Nacional de Aprendizagem Comercial, 1993).

O guia de turismo é partícipe de um processo complexo. Tem por meta encaminhar e orientar as pessoas e tem obrigações, uma vez que o turismo, nos dias de hoje, buscando a obtenção de qualidade, determina as ações. Assim sendo, é preciso oferecer, proporcionar e satisfazer as necessidades de prazer buscadas pelo turista, em uso de seu tempo livre. O profïssional necessita demonstrar toda sua capacidade, criatividade, responsabilidade que cabem em processos de tal natureza. "Quem não tiver competência não sobreviverá", eis a máxima que bem define o que deverá ser, se quiser prosseguir e aumentar os projetos de sua empresa ou da empresa contratante.

A Embraturapresenta algumas considerações sobre controle de qualidade do produto turístico:

Entende-se por controle de qualidade do produto turistico nacional, o conjunto de atribuiçōes exercidas com a finalidade de definir e avaliar padrōes de conforto, higiene, segurança, atendimento e preço de bens e serviços, capazes de satisfazerem a expectativa da demanda interna e externa.

No atual mundo globalizado, a palavra qualidade é chamada para todos os setores e, assim sendo, não deixa de ser também para o Turismo.
Três sāo os elementos importantes para o futuro do turismo: inovação (criatividade, imaginação, questionamentos), desempenho (produtividade) e qualidade (profissionalismo, busca permanente da satisfaçāo do cliente) (Beni, 1990).

O guia de turismo deve possuir habilidade para atuar com todos os itens citados, pois essa é a forma de demonstrar qualidade.

O sucesso de uma atividade turistica depende da qualidade de seus equipamentos, dos prestadores de senviço e da interaçāo entre os elementos componentes (Barreto, 1995).

Dentro da atividade turística - viagens -, a prestação de serviços se dá em vários âmbitos, quer seja equipamento, como hotéis, restaurantes, transportes para o deslocamento, quer seja a atenção permanente da pessoa que acompanha o grupo. Esta é a função do guia de turismo, quando ele deverá demonstrar toda sua capacidade. Em todo momento dará atenção ao viajante e o resultado de um bom atendimento será a fidelidade do cliente.

Fala-se pouco sobre as funções do guia de turismo, ou seja, parecem ser atividades comuns e de conhecimento geral, mas na verdade trata-se de um trabalho meticuloso que exige extremo interesse e adaptabilidade. Nem todos podem exercêla, e as pessoas que executam essa tarefa devem ter algumas características particulares, além de capacidade para aprender e adaptar-se às diferenças pessoais que vão enfrentar. Nãoexisteliteratura a respeito. Apesarde ser uma atividade antiga no Brasil, somente foi considerada profissão a partir de 1986 e regulamentada a partir de 1993. Os autores se referem ao guia como um empregado de agência, de instituição e é mencionado muito brevemente, como elemento secundário. As próprias normas da Embratur enfocam os serviços e esquecem de mencionar quem vai realizá-los.

Até o momento, foram vistas as características positivas de um guia, suas qualidades em formas de atendimento, eficiência, presteza. Também há as negativas, como, por exemplo, as relacionadas à exploração do turista:

A questāo da exploração do turista é também um problema que age em detrimento da qualidade. Em conseqüência do fato de que, historicamente, o turista está de passagem e dificilmente retornará, criou-se um vício, na área, de cobrar preços abusivos e oferecer um atendimento precário. (...)

Isto é mais do que problemático no caso latino-americano, onde a imprevisibilidade das politicas econômicas leva grande parte do empresariado a uma posição imediatista de lucraromáximono menortempo, deixando em segundo plano a preocupação com oretorno do cliente; retorno que só acontecerá se houver satisfação (Barreto, 1995).

Analisando a situação do guia de turismo, o que pode ocorrer é um desvio que gera algumas atitudes inadequadas. É fato comum e real o comissionamento que 
algumas empresas oferecem ao acompanhante da excursão ou ao guia local, no cass de levarem scus grupos até determinado local de comércio, restauração, elc. O recebimento desse comissionamento é tema de inúmeras discussões. O viajantu sempre quercompraralguma lembrança, algum produtotípico c, cm geral, pede ao gui: que o leve ao comércio. Cabcao guia indicar onde adquirir boa mercadoria pelo melho preço. A comissão pode ser accita como uma gentileza da casa, mas não deve atcrse a esta como motivação para a recomendação. Aqui ocorrem os maiores desvios c há exageros tão acentuados que chegam a dar "má fama" à profissão. Todo esse processo não tem regulamentação oficial e fica somente no âmbito da ética profis. sional.

Os turistas sabem que o comissionamento é natural e eles não sc incomodam que seu acompanhante reccba a gratificação, se sentirem que cle é honesto e está levando-os a um bom local, com preços razoáveis. O mesmo vale para a atitude contrária, ou seja, os turistas odiarão o guia, se sentirem que estão sendo explorados. E essa reação reflete-se diretamente contra a agência, cmpresa, instituição. $\Lambda$ propaganda "boca a boca" será feita de imediato e, como se sabe, as notícias negativas espalham-se rapidamente, dispondo o turista contra a agência e esta contra o guia de turismo.

Considerando os profissionais que não têm ética nem critérios e abusam, desrespeitando os interesses dos viajantes, a Embratur, visando a qualidade, e como entidade determinadora dos serviços turísticos, começou a exigir, a partir de 1986, que os elementos que costumavam acompanhar os viajantes, passassem a fazê-lo com método e de acordo com algumas premissas preestabelecidas. Determinou, então, a obrigatoriedade de que cada guia de turismo estivesse cadastrado ${ }^{3}$ junto ao Instituto Brasileiro de Turismo, mas que o fosse após a assistência a um curso específico, credenciado por esse Instituto.

Tal determinação, que continua até os dias atuais, cstabelece cursos que preparam guias de turismo de acordo com normas definidas pela Embratur e aprovação pelos Conselhos de Educação. Assim, esta cntidade indica conteúdos e critérios que serão desenvolvidos por estabelecimentos cducacionais, como faculdades e escolas técnicas. A seguir, os Conselhos Estaduais de Educação (em casos de entidades particulares, o próprio Conselho Fedcral de Educação) definem o número de horas, métodos, docentes, etc. e também estipulam o caráter da habilitação, conforme as necessidades regionais c do mercado, assim como os períodos em que se deverão realizar. São cursos nas categorias de guias regionais, guias de excursão nacional c internacional e guias especializados. A característica de tais cursos é de nível técnico profissionalizante, com exigência mínima de $2^{\circ}$ grau completo.

As especificações das categorias guia de excursão e guia especializado são:

\footnotetext{
3. As categorias de guia de turismo cadastradas pela Embratur sāo: Guia Regional, Guia de Excursāo Nacional, Guia
} de Excursão Internacional, Guia Especializado em atrativo turístico natural ou cultural (ecológico, náutico, arte
barroca, etc.), conforme artigo $3^{\circ}$, inciso IV da Deliberação Normativa n. ${ }^{\circ} 32.5$, de $13 / 1 / 94$.
Guia de Excursão - Atividades que compreendem o acompanhamento e a prestação de informações e assistência, em caráter permanente a grupos de turistas, em suas viagens e deslocamentos entre diferentes localidades integrantes do programa de excursāo, para $\circ$ atendimento dos roteiros ou itinerários turísticos, previamente estabelecidos, de âmbito nacional ou internacional.

Guia Especializado - Atividades que compreendem especificamente a prestaçāo de informações técnicas especializadas relativas a:

- determinado tipo de empreendimento ou atrativo turistico natural;

determinados tipos de roteiros turisticos de cunho cultural, econõmico, desportivo, técnico-profissional ou similar, inclusive roteiro hidroviário (Serviço Nacional de Aprendizagem Comercial, 1993).

Com a comprovação de estudos de $2^{\circ}$ grau e o curso completo, o interessado deve dirigir-se ao Instituto e solicitar seu cadastro de guia de turismo da Embratur, na categoria para a qual se habilitou. Também são exigidos o pagamento do Imposto sobre Serviços (ISS), e o cadastro no Instituto Nacional de Seguridade Social (INSS). Há poucos anos a profissãoé exercida de modo oficial e dentro dos critérios exigidos, por isso ainda não houve tempo para abranger todo o mercado e há muita difículdade de fiscalização, de modo que são encontrados muitos casos de pessoas não credenciadas atuando e, não menos vezes, elementos que não cumprem as regras estabelecidas.

A classe tem lutado bastante e tem conseguido vitórias expressivas. A primeira e mais importante foi em $1^{\circ}$ de outubro de 1993, através do decreto n. 946 com a regulamentação da lei n. 8.623, de 28 de janeiro de 1993, que dispõe sobre a Profissão do Guia de Turismo. Foi conquistada pelos guias atuantes no País, através de pedidos e solicitações a deputados, ministros e ao presidente da República. Resultou num ganho que orgulha a todos e os leva a compreender com responsabilidade a importância de sua atuação. É importante também lembrar que entre os profíssionais do Turismo, a única categoria que tem a profïssão regulamentada e oficializada, é a dos guias de turismo. Os agentes de viagens, apesar de formarem uma classe bem mais antiga, ainda não obtiveram essa condição.

Hoje em dia há 9.191 guias de turismo credenciados pela Embratur em todo Brasil. A relação dos guias está agrupada por regiões e Estados da Federação. Destacam-se alguns números: na região Sudeste, com 5.763, sendo a liderançado Rio de Janeiro com 3.480 e 1.621 em São Paulo; na região Sul, com 1.534, dos quais 326 em Santa Catarina; na região Nordeste, com 1.356 guias cadastrados. Esses profissionais estão capacitados e foram preparados para proporcionar ao viajante o melhor atendimento possível. Todos obtiveram sua habilitação através de cursos técnicos profissionalizantes ministrados por instituições responsáveis e idôneas, como o Serviço Nacional de Aprendizagem Comercial (SENAC), e universidades que possuem curso de Turismo e o SINE.

Além de conhecimentos de conteúdos como história, geografia, primeiros socorros, comunicação, legislação, etc., também são vistos, nos cursos preparató- 
rios, situações de relações humanas e trcinamento em atividades práticas e técnicas específicas à profissão de guia de turismo, em suas diversas categorias.

São realizadas, em média, três viagens em cadacurso, plancjadas, organizadas, preparadas e executadas pelos próprios alunos, com orientação c supervisão de um profissional habilitado. Os idiomas também merecem cspecial atenção, considerando-se sempre a região ondc é rcalizado o curso c o tipo de habilitação que oferecc.

\section{Guia e Turista}

O turista é um passageiro em busca de momentos agradáveis que lhe possam proporcionar o descanso merecido de atividades constantes exercidas durante todo o ano de trabalho. A viagem ou passeio deve trazer-lhe prazer e precisa ser perfeita. Nesse momento, o turista não pensa na imperfeição humana, problemas não devem acontecer nas suas férias.

\begin{abstract}
Ao abordar os aspectos técnicos da comercialização do produto turistico, não devemos deixar de considerar que, ao vendê-lo, o profissional estará tratando com pessoas que acalentaram, durante $\mathrm{o}$ ano inteiro, $\mathrm{o}$ sonho das suas férias. $\mathrm{O}$ aspecto humano $\mathrm{d}$ atividade não poderá ser suplantado por sofisticados planos mercadológicos, modernas técnicas de venda ou por uma publicidade agressiva, pois, sem dúvida, o melhor divulgador de um produto turistico é um cliente satisfeito com as experiências vividas durante a sua viagem (Ruschmann, 1991).
\end{abstract}

A agência procurou agradá-lo, contratou os melhores serviços, efetuou uma venda com todos os requisitos de atenção, mas podem acontecer imprevistos. Seguramente o viajante ficará frustrado, insatisfeito e irá reclamar da qualidade, a não ser que seu acompanhante saiba resolver de forma satisfatória os impasses. Muitas vezes, com cmpenho, ele conseguirá reverter os problemas, mas se isso não estiver ao scu alcance, devcrá proporcionar outras atençõcs ao cliente para que seu desconforto seja atenuado. Às vezes ouvem-se comentários de passageiros, como:

O hotel era horrivel, mas o guia nos fez participar de tantas atividades, era tão gentil e atento que nãotinhamos tempo para observar detalhes do hotel. A comida era um espanto mas ele conseguiu que nos melhorassem as refeiçōes.

Cada passageiroé um indivíduo e tem suas próprias características. O guia de turismo não poderá "catalogar" um determinado grupo pelas semelhanças que existam. Ele precisa adaptar-sc a todos e estar permanentemente atento a qualquer tipo de preconceito ou preferência. Assim, antes de receber um grupo, o guia deve contatar a agência e verificar a faixa elária dos componentes do grupo, suas prolissões (caso seja possível), o objetivo da viagem, a origem dos elementos do grupo e outros interesses que possam existir, para poder planejar suas atividades e propor-sc a receber o grupo com simpatia e isenção de opinião. A improvisação deve limitar-se à solução de imprevistos.

O maior grupo de turistas que movimenta o segmento mais sofisticado do turismo mundial são os formados pelos povos americano e europeu. Na maioria são pessoas da chamada "Terceira Idade", com boa aposentadoria de seus fundos de pensōes e situação financeira privilegiada. Estes turistas são os responsáveis em atender à demanda dos pólos turisticos mais sofisticados do mundo.

Milhōes dessas pessoas têm tempo livre, têm dinheiro para gastar e viajam até as mais diversas regiōes do planeta em busca de cenários bonitos, museus, cultura e religiosidade. Entre as diversas exigências que eles fazem destacam-se a cordialidade, conforto e segurança. Segurança fisica e segurança de sua saúde (Lopes,1994).

O Brasil recebe poucos grupos com as características apontadas por Lopes, mas tem-se grupos de Terceira Idade, que sãomuitoatuantes e recebem apoio especial da Embratur. Embora não sejam pessoas com tanta disponibilidade financeira, dispõem de tempo e vontade, viajando bastante. O guia de turismo, ao receber grupos desse tipo ou grupos de jovens, de casais com fillhos pequenos, deve tomar as devidas precauções no que se refere ao atendimento, considerando que os interesses serão diversos. Isto significa que o técnico deve estar sempre estudando e adaptando-se às pessoas com quem vai conviver e orientar durante certo tempo. É necessário que interprete o quê o turista quer: a busca do prazer e da satisfação (Lopes, 1994).

Há maior dificuldade quando o grupo está formado por elementos de várias faixas etárias, diversas origens, religiões, ocupações. Nestes casos espera-se do profissional uma grande parcela de adaptabilidade às situações e muita criatividade. No entanto, ele sempre será o alvo das atenções de "seus" passageiros e seu modelo será seguido. Embora suficientes, "sabidos" e autônomos, em geral os turistas querem apoiar-se nos conselhos do guia e fazer o que ele determinar.

Considerado o aspecto modelo, convém en fatizar não só a importância do guia como orientador e acompanhante, mas a necessidade de que esteja bem preparado, tenha conhecimentos técnicos e de cultura geral, consciente do papel que desempenha, pois irá atingir níveis muito amplos nesse contato com o turista.

Guia de Turismo lida predominantemente com pessoas, podendo agir livremente ou supervisionado, sendo seu trabalho rotineiro, no que diz respeito à execução de suas tarefas.(...)

Existem duas formas do Guia exercer sua profissão:

Guia Autônomo-aquele que trabalha individualmente oferecendo às diversas agências o seu serviço.

Guia de Agência - aquele que está filiado a uma Agência especifica e só atende os grupos organizados pela sua Agência (Serviço Nacional de Aprendizagem Comercial, 1993). 
As empresas brasileiras de grande porte, que recebem turistas e também os enviam ao Exterior, consideram o guia de turismo um ponto positivo na viagem turística. Essas empresas têm selecionado guias credenciados pela Embratur, abolin do as práticas anteriores de colocar qualquer pessoa para acompanhar o viajante. Além disso, os profissionais têm sido treinados com as normas dessas empresas, de forma a compor um quadro homogêneo, com atuação uniforme de todos os componentes. Traça-se assim uma linha de atendimento, somada a outras atividades da empresa, como organização, planejamento e venda de destinações turísticas.

\section{Guia de Turismo e Relaçōes Humanas}

O guia de turismodeverá proporcionar o atendimento direto ao viajante e, para tal, deverá seguir algumas regras básicas de relações humanas. Diz Wöhlke (1995), que

as Relações Humanas impõem uma série de medidas, observadoras da comunicação, da educação, da ética profissional e da eficiência.

Ele tcm obrigação de conhecer, executar e absorver conceitos e práticas que o tornarão uma pessoa aceita e apreciada pelos turistas: olhar para as pessoas, cumprimentá-las, ouvir com atenção, ter ética profissional, demonstrar uma boa educação, ser eficiente.

O lema "o cliente sempre tem razão" deve balizar todas as ações empresariais e promocionais.(...) as pessoas não querem só ver coisas ou objetos; elas querem é ouvir histórias, lendas e aprender um pouco mais da cultura dos povos (Lopes, 1994).

O guia deve conhecer a história básica dos locais que visita, adquiridas no curso ou através de estudos, mas deve também se comunicar com os moradores locais, pois só através de conversas com eles é que conhecerá as lendas, os contos que fazem a mística. Essa mística é atrativa para os turistas. É "o algo mais que se oferece", paralelamente à visita em si.

A necessidade de relacionamento do técnico não se atém somente ao contato com o turista. Ele também deve manter relações cordiais, de integração e intercâmbio, com outros profissionais do turismo, como motoristas, guias regionais ou locais, agentes de viagens, transportadoras, etc. O sucesso de uma excursão pode depender da integração e harmonia entre o trabalho de todos os agentes de Turismo.

No caso de viagem rodoviária, o guia de excursão tem no motorista o seu maior parceiro e é preciso estabelecer uma relação de amizade com muito profíssionalismo entre ambos. Ele é a autoridade máximadurante uma viagem, porém deve discutircom o motorista sobre roteiro, estradas, atalhos e paradas técnicas, pois é a pessoa que está constantemente viajando e espera-se que conheça bem os itinerários a cumprir Por outro lado, cabe ao condutor a segurança de todo o grupo, podendo facilitar consideravelmente o trabalho do responsável pela viagem.

O guia local contratado em cada cidade visitada é seu colega especializado para aquela área e assume toda a responsabilidade perante o grupo. Assim sendo, o responsável pela excursão servirá de respaldo, mas não deverá interferir no seu trabalho e orelacionamento entre ambos deve ser cordial e amistoso. No caso do guia local a recíproca é verdadeira: ele deverá dar as informações devidas sem envolverse na programação que está a cargo do guia de excursão. Os prestadores de serviços, que atuam direta ou indiretamente com os turistas no desenvolvimento de uma programação, trabalham com o guia e não para o guia, o que deve estar muito claro na compreensão de ambos. Os laços de amizade podem proporcionar muita segurança e é digno recordar que cortesia, respeito e atenção não fazem mal a ninguém.

\section{Perfil do Guia de Turismo}

Já se comentou que muitas vezes o guia não é considerado, não é reconhecido, e seu trabalho ocorre na surdina e parece ser insignificante. Tanto é desconsiderado que sequer sua titulação profissional é devidamente conhecida pelos turistas que o acompanham e pelo público em geral. Comumente se escuta dizer o "guia turístico que nos acompanha", quando o significado de guia turístico nada mais é que o livro onde são encontradas as informações turísticas. O guia de turismo é o nome correto do profissional que deve ter uma série de capacidades e qualidades, tendo por tarefa primordial fazer cumprir, junto ao turista, os serviços que foram por este contratados.

Essa pessoa necessita despojar-se de todas suas cargas emocionais particulares para poder participar com o turista de seus momentos mais importantes que são a realização de uma viagem que, possivelmente, tenha sido seu sonho por muito tempo.

Giacomini Filho (1997) comenta sobre o nível das ofertas que as empresas turísticas chegam a fazer aos seus clientes, tendo em vista o grau de expectativa a alcançar. Assim, o que pode surpreender o turista de modo agradável, por outro lado poderá talvez descontentá-lo. Tudo ficaria no âmbito de uma pesquisa prévia sobre os interesses que, por sua vez, seriam extremamente variáveis, tendo em vista a diversidade do público que transita na atividade turística.

Para um bom guia, isso não deve passar de um mero exercício de "jogo de cintura". A empresa contratante deixaria a seu critério tratar os passageiros com a oferta básica, a esperada, a desejada ou até a inesperada. No decorrer de sua atividade junto ao grupo ele vai perceber quais os interesses e qual a aceitação. É preciso que tenha autonomia para proceder como seja melhor para o cumprimento do que foi prometido. Por outro lado, também é preciso que tenha plena confiança na empresa que o contratou, pois assim se sentirá com liberdade para atuar $\mathrm{cm}$ benefício do cliente. 
Vários instrutores organizaram uma série de itens que podem representar 0 perfil do guia de turismo. Na verdade, não há estudos específicos sobre o assunto, tampouco regras psicológicas a seguir, é somente uma constatação de experiência.

O profissional é um espécie de anfitrião e todas suas iniciativas tendem para a busca do "bem-estar do turista". Ele recepciona os componentes do grupo e encarrega-se da execução de todo o roteiro de viagem. É o elemento de ligação entre o excursionista e os órgãos de prestação de serviços. Para que possa desenvolver adequadamente suas funções, fazem-se necessários os seguintes requisitos:

- ter o completo conhecimento do roteiro de viagem, dos equipamentos receptivos e complementares;

- ter conhecimentos para responder satisfatoriamente a todas as perguntas feitas pelo turista ou dispor-se a conseguir as informações necessárias;

- conservar a expressão sempre alegre e saudável, ter boa resistência física;

- possuir boa aparência, principalmente na parte higiênica;

- apresentar-se sempre bem vestido, com discrição (vestir-se negligentemente é falta de atenção para com os outros), portando o crachá de identificação da empresa ou pessoal;

- ter conhecimentos sobre percepção social;

- saber utilizar o mais adequado sistema de comunicação;

- falar com boa dicção, naturalidade e desenvoltura em tempo razoável para não cansar o ouvinte;

- expressar boas maneiras no trato social

- agir com bom senso, naturalidade e confiança quando surgirem situações imprevistas;

- ser um líder integrador;

- ser paciente, tolerante e atencioso;

- ser responsável, organizado e pontual;

- possuir boa memória e equilíbrio emocional.

\section{Considerações Finais}

O guia de turismo tem uma responsabilidade muito grande. É possível dizer que ele é o elemento que abre, desenvolve e encerra a viagem turística. A venda de uma programação pode ser resultado de um trabalho anterior atento e, seguramente será a indicação para uma próxima.

Trabalho profissional, boa atuação e propaganda podem promover a venda de novos pacotes turísticos para a agência, pois com um bom guia dificilmente 0 passageiro recusará a oferta de mais uma viagem. Isto representa a qualidade de uma prestação de serviço efetiva.

Durante todo o percurso, o técnico estará vivendo uma aventura lado a lado com seus passageiros. Serão momentos de confraternização e cumplicidade na execução de um programa específico. O encantamento de uns coincidirá com as expectativas de outrose, ao término da viagem, todos se congraçarão em uma análise dos prós ou contras. O guia capacitado tem a oportunidade, durante o tempo de convívio, de fazerencantar-se, demoverdificuldades, esclarecer dúvidas, relacionarse e, ao final, chegar a conclusão satisfatória para todos: turistas, agência e sua própria pessoa.

É claro que todas estas afirmativas são utópicas. Nem sempre as coisas ocorrem dessa forma. Mas com boa atuação do profissional, há possibilidade de se conseguir que as dificuldades sejam amainadas e quase relegadas ao esquecimento, prevalecendo os acontecimentos positivos ocorridos na viagem. Sem dúvida esse fato será um bom encerramento para a atividade.

O guia de turismo é importante para o viajante que nele se apóia, mas também para a agência que o contrata e, principalmente, para a atividade turística em geral. Ele se torna o elo entre a execução do programa pela agência e o amparo na legislação, ao mesmo tempo que colabora com a satisfação plena do consumidor.

$\mathrm{O}$ trabalho que tem sido desenvolvido por esse profissional do turismo vem repercutindo de forma positiva dentro do contexto brasileiro. Finalmente, é imprescindível que o guia seja mais considerado e valorizado pelas empresas turísticas e possa atuar auxiliando o turista a atingir o nível máximo de satisfação e prazer.

\section{Referências Bibliográficas}

ANDRADE, José Vicente de. 1995. Turismo: fundamentos e dimensões. São Paulo: Ática. BARRET@, Margarita. 1995. Manual de inicią̧ão ao estudo do turismo. Campinas: Papirus, BRASIL. Decreto n. 84.934, de 21 de julho de 1980. Inciso II. Artigo 17.

$$
\begin{aligned}
& \text { Decreto n. } 946 \text {, de } l^{\circ} \text { de outubro de } 1993 . \\
& \text { Lei n. } 8.623 \text { de } 28 \text { de janeiro de } 1993 .
\end{aligned}
$$

BENI, Mário C. 1990. Sistema de Turismo - SISTUR: estudo do turismo face à moderna teoria de sistemas. Turismo em Anúlise, São Paulo, ECA/USP, v. I, n.I.

EMBRATUR. Instituto Brasileiro de Turismo. Brasília. 1983. Resolução normativa CNTUR n. 4 de 20 de janeiro de 1983. Parágrafo 2, artigo II.

$$
\text { 1994. Deliberaçāo normativa n. } 325 \text {, de } 1.3 \text { de janeiro de } 1994 .
$$


GIACOMINI FILHO, Gino. 1997. Empresa turística voltada ao atendimento. Turismo em Análise, Sāo Paulo, ECA/

USP, v.8, n.2, p. 44-58, nov.

LOPES, Ataíde Rodrigues. 1994. O ABC do turismo„ Brasília: A.R. Lopes.

RUSHMANN, Doris.1991. Marketing Iuristico. Campinas: Papirus.

SERVIÇO NACIONAL DE APRENDIZAGEM COMERCIAL. 1993. Manual do Guia de Turismo

WÖHLKE, Renato. 1995. Apostila de guia de turismo nacional. Itajaí: CEPAVI.

YASOSHIMA, José Roberto. 1997. A qualidade na prestaçāo de serviços turisticos. São Paulo: ECA-USP.

(Dissertaçāo de Mestrado).

Recebido em 11/2/99

Aprovado em 20/2/99 